To the Editors:

\title{
Well men clinic service in the primary health care setting
}

In Sri Lanka the primary health care (PHC) services commenced in 1926, with great concern on maternal and child health [1]. More than 5 decades later the World Health Organization (WHO) emphasised prominence to PHC [2]. In 1996 Well Woman Clinics were introduced to combat the emerging epidemic of non-communicable diseases (NCD) [3]. However, men are neglected by the state PHC services in the country. We explored the possibility of commencing a Well Men Clinic (WMC) service in Arachchikattuwa $\mathrm{MOH}$ area as an entry point to screen for NCD and risk factors of NCD.

WMC activities were identified based on the existing WMC in developing countries and the activities of Well Woman Clinics in Sri Lanka [3]. The clinic was conducted by $\mathrm{MOH}$ with the support of Public Health Midwives (PHM) and Public Health Inspectors (PHI). The awareness about the WMC was done by the PHM and PHI during their routine activities. Men aged 35 years or above were encouraged to attend. This age was chosen because the early possible age to detect most of the NCDs and also appropriate time for early effective intervention in terms of prevention of NCD is mid-thirties [4].

The services provided at the WMC were, health education, medical examination (anthropometry, clinical examination and investigations) and appropriate referral.

There were 14 clinic sessions and 301 attendees during the study period. Of them 21 were less than 35 years of age and excluded from the study. The clinics were conducted in 5 PHI areas depending on the availability of facilities. The average time taken to conduct a clinic session was about 4 hours with 20-25 attendees per clinic session. Nearly one third (34\%) of them were referred to the curative sector. Table 1 describes the profile and the referral pattern of the WMC.

Table 1. The service functions and referral practices of the WMC

\begin{tabular}{|c|c|c|c|c|c|c|c|}
\hline \multirow[t]{2}{*}{ Service function } & \multicolumn{5}{|c|}{ PHI Area } & \multicolumn{2}{|c|}{ Total } \\
\hline & 1 & 2 & 3 & 4 & 5 & & \\
\hline \multicolumn{8}{|l|}{ WMC pattern } \\
\hline Number. of clinics conducted & 4 & 4 & 4 & 1 & 1 & 14 & \\
\hline $\begin{array}{l}\text { Number. of participants } \\
\text { (all including <35 years) }\end{array}$ & 113 & 76 & 65 & 21 & 26 & 301 & \\
\hline $\begin{array}{l}\text { Number. of study participants } \\
\text { (all including } \geq 35 \text { years) }\end{array}$ & 111 & 69 & 58 & 21 & 20 & 279 & \\
\hline \multicolumn{8}{|l|}{ Referrals } \\
\hline \multicolumn{8}{|l|}{ Referred institutions } \\
\hline Primary care institutions & 1 & 5 & 7 & 1 & 5 & 19 & $(20.2 \%)$ \\
\hline Secondary care & 36 & 16 & 14 & 5 & 4 & 75 & $(79.8 \%)$ \\
\hline \multicolumn{8}{|l|}{ Referral category } \\
\hline Medical clinic & 29 & 13 & 8 & 5 & 3 & 58 & $(61.7 \%)$ \\
\hline Surgical clinic & 2 & 1 & 2 & 1 & 1 & 7 & $(7.4 \%)$ \\
\hline *Other & 6 & 7 & 11 & 0 & 5 & 29 & $(30.9 \%)$ \\
\hline No. of referrals followed up & 30 & 17 & 19 & 4 & 9 & 79 & $(84.0 \%)$ \\
\hline No. complied & 21 & 11 & 15 & 4 & 8 & 59 & $(62.7 \%)$ \\
\hline No. not complied & 9 & 6 & 4 & 0 & 1 & 20 & $(21.3 \%)$ \\
\hline Back referrals & 0 & 0 & 3 & 0 & 6 & 9 & $(9.6 \%)$ \\
\hline
\end{tabular}

1 - Bangadeniya, 2 - Rajakadaluwa, 3 - Anawilundawa, 4 - Baththulu Oya, 5 - Wilpotha

* Includes referrals to psychiatry, dermatology, ophthalmic, and outpatient department clinics 
Attendance at the Well Woman Clinics in the same setting over a six-month period in 2005 was much less. The increased attendance at WMC could be due to the novelty of this activity and a previously unmet need. Sustainability of the attendance in a WMC will be a future challenge.

The group health education session at each clinic session did not take place due to scattered attendance pattern. Posters and leaflets or a brief health talk given repeatedly may help.

The Benedict's test for urine sugar and heat coagulation test for urine albumin are crude laboratory tests which are cost-efficient and reliable in the hands of trained midwives and nurses. Availability of laboratory investigations will make the WMC more acceptable to the public.

\section{Acknowledgement}

Staff of Arachchikattuwa MOH Office are thanked for their co-operation.

\section{References}

1. Hewa S. Colonialism, Tropical Disease, and Imperial Medicine: Rockefeller Philanthropy in Sri Lanka. Lanham, Md: University Press of America, 1995.

2. World Health Organization. Report of the International Conference on Primary Health Care. WHO (Geneva) 1978.

3. Handbook on Well Women Clinics. Family Health Bureau 2003, Colombo.

4. World Health Organization. Preventing chronic diseases: a vital investment: WHO global report. WHO (Geneva) 2005; 01-03.

\section{A P de Silva ${ }^{1}$, Ananda Amarasinghe ${ }^{2}$, Saroj Jayasinghe ${ }^{3}$ and R M S K Ratnayake ${ }^{4}$}

${ }^{1}$ Postgraduate Trainee, Postgraduate Institute of Medicine, Colombo. ${ }^{2}$ Assistant Epidemiologist, Epidemiology Unit, Colombo. ${ }^{3}$ Professor, Department of Clinical Medicine, Faculty of Medicine, University of Colombo. ${ }^{4}$ Regional Director of Health Services, Puttalam District.

Correspondence: APDS, e-mail <pubsy@s/tnet.lk.> Received 5 October 2007 and revised version accepted 12 March 2008. Competing interests: none declared.

\section{Pain of mind}

Pain of mind is worse than pain of body.

Publilius Syrus, Roman Dramatist. ( $1^{\text {st }}$ century BC). 